\section{Method for Measuring the Leaf Surface Area of Complex Shoots}

A KNOWLEDGE of leaf surface area is essential for many plant physiological and ecological studies ${ }^{1-5}$. Conventional measurements based on leaf dimensions are invariably laborious and often only approximate. Other methods aimed at increasing the speed and accuracy of the measurements, such as photoelectric techniques ${ }^{6,7}$, are only really applicable to broad leaved species. For microphyllous and needle leaved species the only reliable method so far has been to calculate the surface areas of selected leaf samples from measurements of length and circumference, then to extrapolate the values to whole shoots on the basis of leaf numbers or fresh weights ${ }^{5,8}$. Doronichev ${ }^{9}$ has attempted to simplify the measurements for conifer shoots by determining the adsorption of methylene blue from aqueous solutions on the assumption that a monomolecular layer is formed on the surface and that each mg methylene blue adsorbed corresponds to a surface area of $1.05 \mathrm{~m}^{2}$. For most plant shoots, however, the change in methylene blue concentration is far too small to be accurately measured using standard photo-densitometers.

We have developed a method on somewhat similar principles that is much more applicable for general use. A shoot is removed and thinly coated with the pressure sensitive adhesive, 'Adsol 400' (Adhesive Solutions Ltd, Rickmansworth), by dipping it two or three times into a solution diluted $1: 7$ by weight with benzene. After about $5 \mathrm{~min}$, to allow the benzene to evaporate, the shoot is weighed and then covered with small Ballotini glass balls (Jencons (Scientific) Ltd, Hemel Hempstead) by pouring the balls over the shoot whilst it is slowly rotated. The shoot is then vigorously tapped or shaken to remove loose balls and reweighed. The balls form a uniform layer over the whole of the exposed surface (Fig. 1), so the gain in weight is directly proportional to the area covered. Leaf and stem surface areas can be separated by removing the needles and repeating the exercise on the stem only, after washing off the balls and adhesive with benzene.

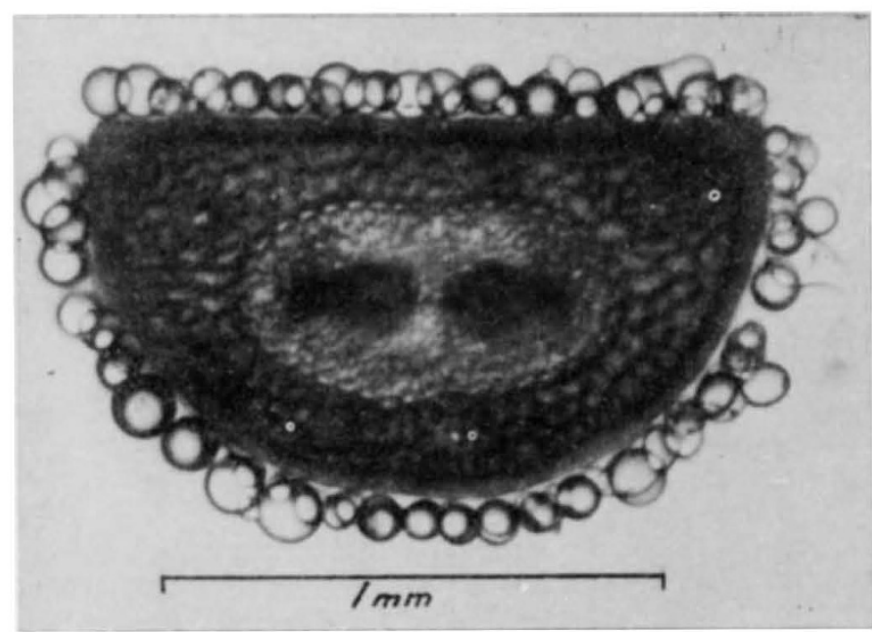

Fig. 1 T. S. Corsican pine needle coated with Ballotini glass balls.

Tests on a range of artificial flat and cylindrical surfaces showed that balls of approximately $0.11 \mathrm{~mm}$ diameter gave the best compromise between a large weight increase per unit surface area and a more consistent packing distribution. For this size of glass ball, the gain in weight was $13.6 \pm 0.1 \mathrm{mg} \mathrm{cm}^{-2}$.

For several Norway spruce shoots (single needles), leaf surface areas determined by the glass ball method and ranging from 17 to $30 \mathrm{~cm}^{2}$ agreed to within $3 \%$ (s.e. $\pm 1.4 \%$ ) with those calculated from the dimensions of a $15 \%$ random sample of needles. For each shoot, the glass ball method took 10-15 min, the conventional method several hours. In the case of mature or near mature Scots pine shoots, the situation is rather more complicated because most of the paired needles are separated at various distances from the base so that the exposed needle surface area as measured by the glass balls is less than the total surface area. When allowance was made for this in the direct measurements, the two methods again agreed to within $3 \%$ (s.e. $\pm 0.1 \%$ ) for areas of 26 to $34 \mathrm{~cm}^{2}$. In many physiological studies, for example, those concerned with gaseous exchange or evaporation, a knowledge of the exposed area of leaf surface is probably more relevant than that of the total surface area. The method can be readily adapted, however, to give total leaf surface areas, for example, by removing one of the needles from each pair so that half the total leaf surface area can be determined.

This new method is simple, rapid and, as far as we can judge, accurate; because it is non-destructive, measurements can be replicated on the same shoot. It can also be used for other complex structures, provided that these are sufficiently rigid to prevent adhesion between surfaces when the adhesive is applied. Different Ballotini ball grades can be chosen according to the detail of the surfaces studied and the precision required. It is important in practice to use dilute solutions to avoid loss of surface detail through the accumulation of the adhesive; with the ridged stems of Scots pine, for example, covering with adhesive decreased the circumference by about $4 \%$. Because of the need to ensure a complete and uniform coating of all surfaces with the balls, a fluidized air bed method may prove more effective than the simple pouring system used here; but our experience has been that the latter method is satisfactory for most purposes.

\section{F. B. THOMPSON}

L. LEYTON

\section{Department of Forestry, \\ University of Oxford, \\ South Parks Road, \\ Oxford $O X 1 R B$}

Received September 21; revised November 22, 1970.

1 Higgins, J. J., Hann, J. R., and Koch, E. J., Agron. J., 489 (1964).

2 Pearce, R. B., Brown, R. H., and Blaser, R. E., Crop Sci., 5, 553 (1965).

3 Welbank, P. J., French, S. A. W., and Ouitts, K. J., Ann. Bot., 30, 291 (1966).

${ }^{4}$ Waggoner, P. E., Furnival, G. M., and Reifsnyder, W. E., Forest Sci., 15, 37 (1969).

5 Landsberg, J. J., and Ludlow, M. M., J. Appl. Ecol., 7, 187 (1970).

6 Moelker, W. H., Plant Soil, 25, 305 (1966).

7 Murata, Y., and Hyashi, K., Proc. Crop Sci. Soc. Japan, 36, 463 (1967).

${ }^{8}$ Madgwick, H. A. I., J. Foren., 62, 636 (1964).

9 Doronichev, N. I., Lesoved, 5,93 (1969).

\section{Bats and Fog}

ON windless evenings fog commonly forms in dense, sharply defined patches, especially in sheltered bays of ponds. As the evening progresses and the temperature falls, these patches may grow and coalesce, advancing over the pond but maintaining a sharp front at which visibility changes profoundly within a few metres. In such conditions insectivorous bats hunting over the water have been observed to turn back at the fog front as if at a solid wall, even though their hunting area may become severely restricted. This behaviour suggests that fog may have a direct effect on echo location. 